\title{
REVIEW ON THE FATIGUE BEHAVIOR OF THE WHEELS OF RAILWAY VEHICLES IN CONTACT WITH RAIL
}

\author{
Constantin Silviu TOTH, Silviu Dănuți MĂCUȚĂ \\ "Dunărea de Jos" University of Galati, Faculty of Engineering, Department Mechanical Engineering \\ 111 Domnească Street, RO-800201, Galati, Romania \\ * Corresponding author: silviu.toth@ugal.ro
}

\begin{abstract}
Rail transport is essential to the EU's strategy for a more sustainable transport sector, economic and social cohesion and connecting Europeans at and between each Member State. EU trend is to support the railway sector as a clean, main mode of transport at European level. The European rail system carries around 1.6 billion tones of freight and 9 billion passengers each year. The railway sector has a substantial contribution to the EU economy, directly employing over 1 million people. With the technological evolution of railway vehicles, it is important to focus on safety issues. Wheels are one of the most critical components of railway vehicles, as their failure can lead to derailment. Therefore, an exact project on the control of the problem of wheel fatigue and knowledge of the effective parameters on their life, can improve the life of the whole structure. Due to the fact that the nature of the loads applied to the wheels is repeated, fatigue is a very common mechanism of damage that can occur in several ways, such as: nucleation and growth of fatigue cracks, spalling, shelling, and so forth. The main sources of these phenomena are the rolling contact loads, the thermal loads between the wheel-rail and the wheel-brake block, created in the braking phase, the presence of structural defects in the wheel material; it follows that they cannot be omitted in a rigorous design. Increasing of speed aggravates these factors and exacerbates the problem of thermal fatigue of the wheels. In this paper we present a series of studies that focused on the wear of the wheels of railway vehicles in contact with the steering track (rail) to fatigue.
\end{abstract}

Keywords: Railway, wheels, structural defects, fatigue cracks, spalling, shelling

\section{INTRODUCTION}

In this paper we present a series of studies that focused on the fatigue behavior of the wheels of railway vehicles in contact with rail, also known as $(\mathrm{RCF})$ "Rolling contact fatigue" RCF describes the process in which cracks grow as a result of the contact stresses between a rolling wheel and the rail. Both normal and tangential stresses are required in order for RCF to develop.

In this perspective, rolling contact fatigue (RCF) of railway components is a most crucial subject. RCF-caused accidents may not only cause personal injuries and economical costs, they may also tend people to commute by car, which further increases traffic congestion, causes environmental problems and eventually may lead to an increase in personal injuries since car traffic is significantly more unsafe than railway transportation. In this concept, also noncatastrophic RCF failures are of importance since they cause unplanned maintenance which eventually causes decreased capacity and delays in the train traffic. [1].

\section{STUDIES AND RESEARCH ON THE FATIGUE BEHAVIOR OF THE WHEELS OF RAILWAY VEHICLES IN CONTACT WITH THE RUNNING TRACK}

\subsection{Crack initiation and growth due to surface plasticity}

When a railway component in rolling contact is subjected to repeated applications of high friction loads (due to traction, braking, curving, etc.), the surface material will deform plastically, see Fig. 1. If the deformation occurs in a dominant direction, the microstructure will show clear signs of being "rolled out" (Fig. 2a). If material hardening and residual stresses are not sufficient to prevent further 
accumulation of plastic strains, cracks will eventually form when the fracture strain is exceeded.

This fracture strain is far above that of tensile tests, the reason being the beneficial influence of the compressive stresses [2]. Such a mode of fracture is referred to as ratchetting and is frequently studied in twin-disc tests (although it has also been studied by biaxial testing [3]). The ratcheting strain has been shown to be a non-linear function of contact pressure and number of contact cycles [4].

In the case of alternating directions of frictional loading (for instance due to alternating traction/braking), the material will not ratchet in the same manner since plastic deformations will occur in both directions causing the accumulated plastic strain to be close to zero. Failure will instead be caused by low-cycle fatigue. For combinations of low-cycle fatigue and ratcheting, fatigue and ratcheting can be seen as competitive mechanisms [5], [6].

The theory of crack initiation due to plastic deformation of the surface material has a strong support from metallographic studies of fractured surfaces (Fig. 2a). In rails, surface-initiated fatigue typically occurs at the gauge corner, whereas on wheels the surface fatigue damage can be spread all over the tread (Fig. 2b) [1]. The dashed lines indicate material planes before and after deformation

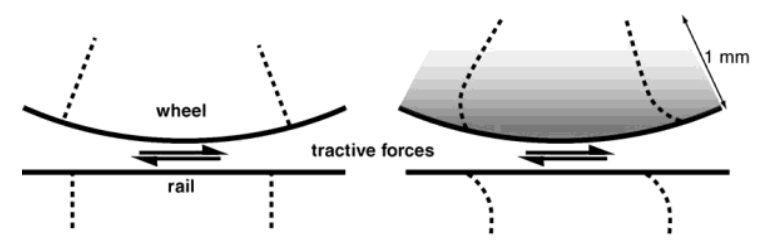

Fig. 1. Schematic sketch of plastic deformation of the surface material in a railway wheel [1]

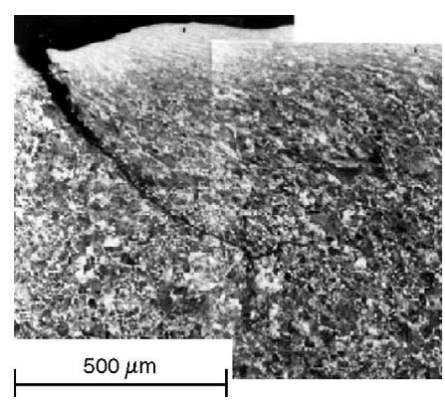

a)

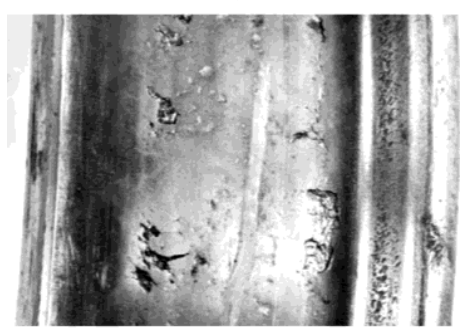

b)

Fig. 2. (a) Deformed microstructure and crack growth in rolling contact. (b) Surface damage due to surfaceinitiated fatigue [7]
Surface initiated cracks initially grow into the material at a shallow angle (corresponding to the texture of the plastically deformed surface material) which soon deviates into an almost radial direction. In railway wheels, the cracks then normally deviates (or branches) again and continues to propagate in a circumferential direction at depths of some 0.5-5 mm [7] (Fig. 3). Final fracture typically occurs as a branching of the crack towards the surface, breaking off a piece of the surface material (Fig. 2b and 3) [1]. At a depth of about half a millimeter, the crack will tend to deviate (or branch) towards a circumferential growth. Final fracture will typically occur as detachment of a piece of the surface material when the cracks deviate towards the surface

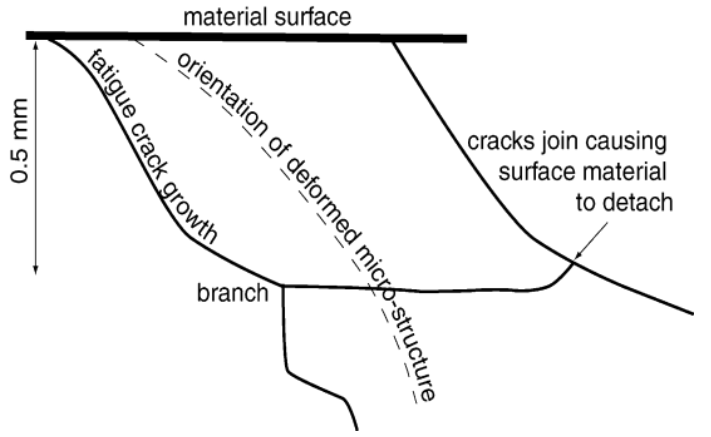

Fig. 3. Schematic representation of growth of surface-initiated fatigue cracks in wheels. Once initiated, the crack will deviate to an almost radial direction. [1].

\subsection{Surface initiated rolling contact fatigue}

In the case of wheel-rail contact, surface initiated rolling contact fatigue cracks typically develop as a consequence of frictional rolling/sliding contact (with possible contributions from thermal loading) that causes plastic flow of the surface material. As the plastic deformation exceeds the fracture strain of the material (significantly increased due to the beneficial effect of the compressive loading), a surface crack is formed. The crack will propagate not only due to the rolling contact loading, but also due to the effect of hydro-pressurization [8]. This effect is caused by a fluid (grease, water etc.) being trapped in the crack. When the crack is being subjected to compressive loading the fluid may lubricate the crack faces, transfer compression to the front of the crack and form an opening pressure on the crack faces. Each of these effects tends to increase the loading of the crack, thus promoting crack growth. [9].

An example of the development of surface initiated rolling contact fatigue in a wheel is shown in Fig. 4. The top picture shows a band of rolling contact fatigue cracks formed towards the field side of the wheel surface (in zone 1, following the classification of [10], presented in Fig. 5). During subsequent operations, the plastic deformation continues, cracks grow and the damaged zones expand. Under detrimental conditions this can be a fairly fast process. In the presented case, the damage 
evolution corresponds to roughly 1 month of operations. [9]. There is roughly 1 month of operational (heavy haul) traffic (in arctic heavy haul conditions) from the RCF initiation in the upper photo to the fully developed RCF cracking in the lower photo.

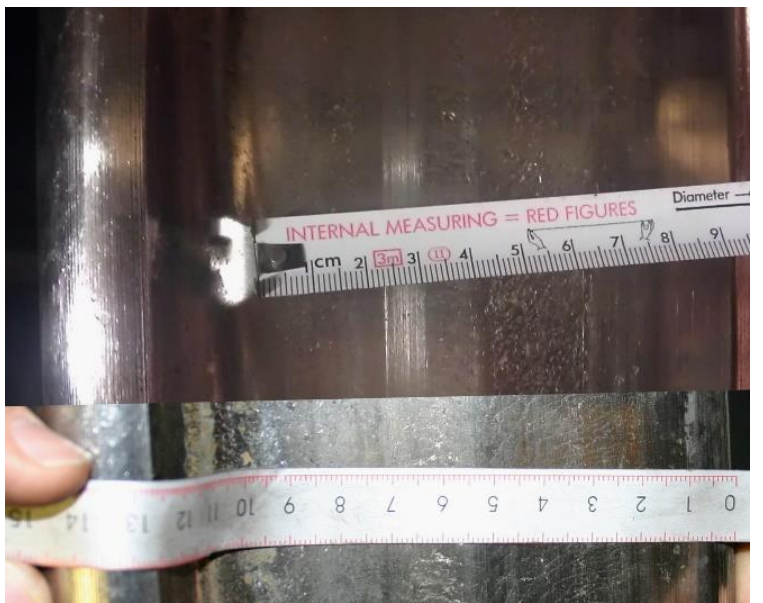

Fig. 4. Development of surface initiated rolling contact fatigue [9]

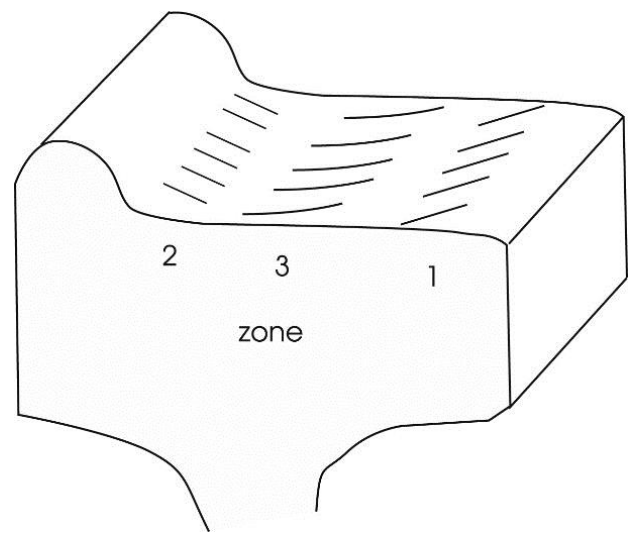

Fig. 5. Definition of zones of rolling contact fatigue on a wheel tread [10]

In order to identify causes of rolling contact fatigue, it is helpful to note that the crack mouth is (ideally) orientated perpendicular to the resultant direction of the frictional force [11]. Thus, it can be deduced that the damage in Fig. 4 is caused by a combination of steering forces on the lower rail during curving (dominating in zone 1) and braking (dominating in zone 3) [9].

In wheels, surface initiated cracks branch towards the surface (unless subjected to severe thermal stresses) and causes surface pitting. [9].

\subsection{Subsurface initiated rolling contact fatigue}

Subsurface initiated rolling contact fatigue is a rather rare, but potentially dangerous phenomenon. It consists of cracks forming below the contacting surface (in a wheel typically at depths $4-25 \mathrm{~mm}$, see [12]). The cracks grow due to the rolling contact and in a wheel eventually branch towards the wheel surface or towards the hub [13]. An example of a failure owing to subsurface initiated rolling contact fatigue is presented in Fig. 6 [9].

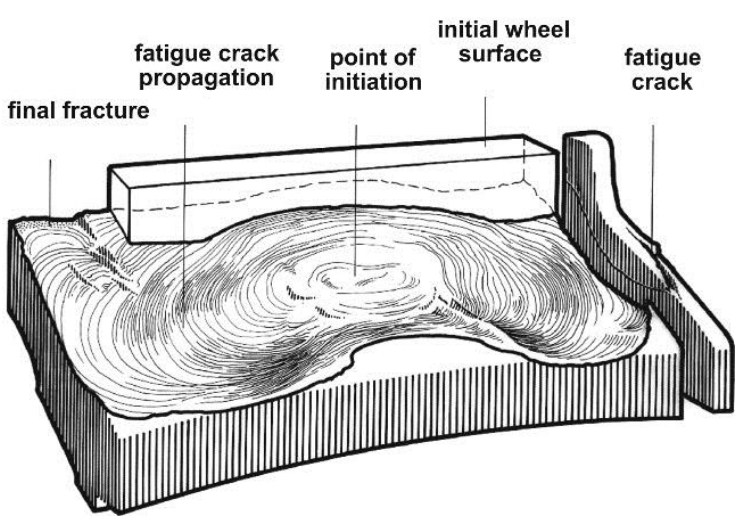

Fig. 6. Example of a failure due to subsurface initiated rolling contact fatigue. Drawing by Ulla

Kjellgren [7]

The initiation is a result of high stress and low material resistance at the point of initiation. Material resistance is here closely related to the material cleanliness, see [14], [15], [16], [17]. A high stress stems mainly from the normal contact force between wheel and rail. In addition, the contact geometry will have an effect in raising stress magnitudes at shallow depths (say 4-10 mm, depending on contact geometry). Further, a contact close to the field side of the wheel has been shown to increase the risk of subsurface fatigue initiation (and gross plastic flow) due to the influence of the free edge, see [18].

It is important to note that it is the combined effect of material defects and high contact load magnitudes that causes subsurface initiated RCF. An example of detrimental operational conditions that can cause subsurface initiated RCF is poorly manufactured and/or maintained rail welds where loss of rail geometry may cause high dynamic loads causing cracks to initiate in weld defects, see [19].

Another example is operations on corrugated rails and/or with out-of-round wheels [20], [21], [9].

\section{The computational approach by Guagliano and Vergani}

The approach for calculating the stress intensity factor of internal cracks under Hertz pressure distribution is divided in two steps (Fig. 7).

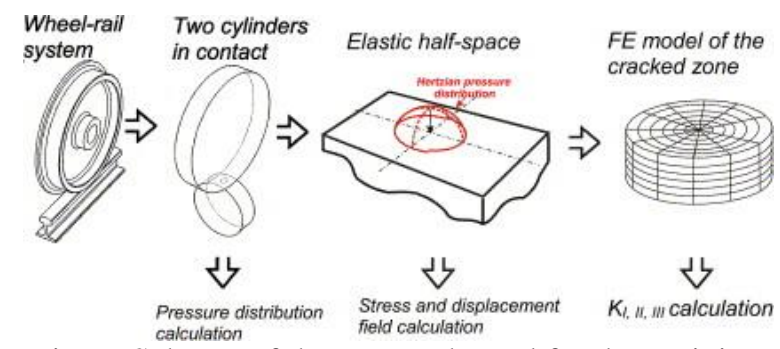

Fig. 7. Scheme of the approach used for determining the stress intensity factors of internal cracks in railway wheels [22] 
The first regards the analytical calculation of the displacement field caused by the Hertzian pressure. In the second step the calculated displacement components are used as boundary condition of a finite element model of the zone surrounding the crack, making possible to calculate the stress intensity factors along the crack front with limited numerical errors (in other words, we use exact boundary conditions) [22].

In the analytical step the wheel-rail system is reduced to two cylinders with perpendicular axes, being the aim the determination of the contact pressure distribution [23]. This latter is used as load condition for the calculation of the stress and displacement distribution in the un-cracked wheel, reduced to a half-space, according to the Bryant and Keer approach [24]. This one was implemented in a symbolic routine written in Maple VII.

The results obtained by this analytical approach are then used as boundary conditions of the FE model of the zone surrounding the crack: in particular, the displacements at the points corresponding to the nodes of the boundary surface of the finite element model are applied to these latter and are used as boundary conditions of the analysis [22].

\section{Finite element modeling of subsurface crack in wheel/rail contact}

Liu et al. [25] proposed a finite element computational methodology for rolling contact analysis of railroad wheels. It has several advantages compared with previous analytical and numerical approaches. First, it is a realistic 3D finite element model and can accurately calculate the $3 \mathrm{D}$ stress response in the contact region. Second, it includes both material and geometric non-linearity, i.e. elastoplastic material behavior and contact stress analysis. It can be used to simulate large and complex wheel motions, such as rotation, sliding, hunting movement and even dynamic impact response. Finally, through sub-modeling techniques, the proposed model is made efficient in computing and hardware requirements.

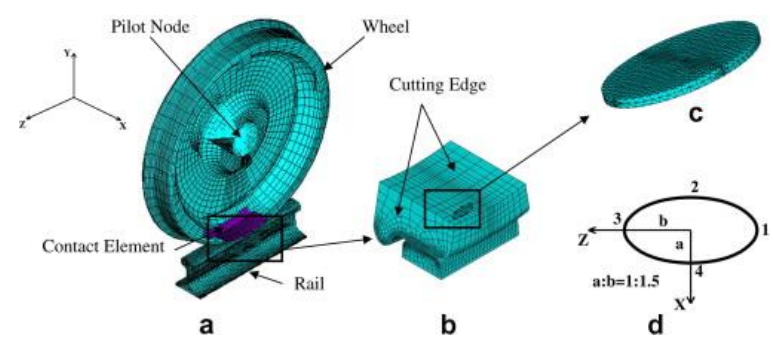

Fig. 8. Finite element modeling of wheel/rail contact with subsurface crack: (a) full model, (b) sub-model, (c) crack and (d) crack shape [26].

Liu et al. [25] used the model for fatigue crack initiation analysis. In this section, the previous developed finite element model is extended for subsurface crack propagation analysis. A brief description of the developed finite element computational methodology is given below, followed by the modification to include a subsurface crack into the wheel [26].

First, use the available profiles to build the geometry model of the wheel and a piece of rail. This model is called the full model as shown in Fig. 8a. Next, quasi-static analysis is performed for the full model and the results for each step are stored. Then the geometry model of the contact region is cut out to create a sub-model as shown in Fig. 8b [26].

The finite element models of the full model, submodel and crack are shown in Fig. 8. The wheel profile is chosen according to the AAR standard [27] wide flange contour.

The static load analysis of the wheel/rail contact is performed first. The results of the sub-model are shown in Fig. 9, Fig. 10. Fig. 9 shows the von Mises stresses from two different section views. Figure 10 shows two in-plane shear stresses $\left(\tau_{x y}\right.$ and $\left.\tau_{y z}\right)$ from two different section views. From Fig. 9, it is found that the maximum von Mises stress occurs at some depth below the tread surface. The stress decreases quickly as the depth increases. The maximum von Mises stress also occurs around the crack tip, which is caused by the stress concentration near the crack tip. From 10, a butterfly pattern of the shear stress $\tau_{y z}$ is observed. The maximum value occurs at the crack tip. Figures 9 and 10 show that the high stress only occurs within a small region of the contact location. The stress in the other parts of the model is almost zero. This indicates that only a small portion of the motion simulation is needed because the stress far away from the contact location is negligible [26].

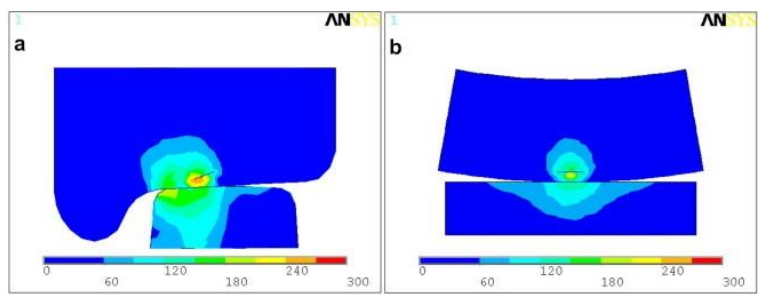

Fig. 9. von Mises stress distribution of wheel/rail contact with subsurface crack (unit: MPa): (a) front section view and (b) left section view [26]

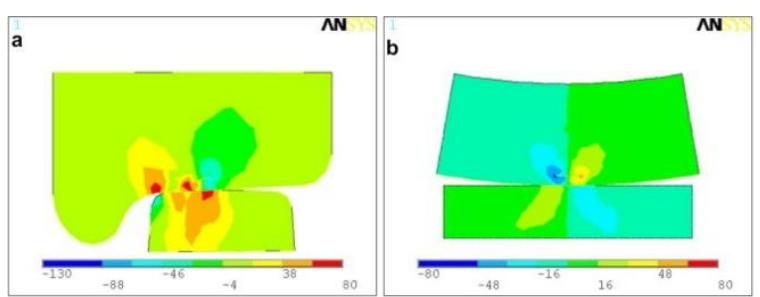

Fig. 10. In-plane shear stress distribution of wheel/rail contact with subsurface crack (MPa): (a) distribution of $\tau_{x y}$ and (b) distribution of $\tau_{y z}$ [26]

After performing the static analysis, the wheel rotation on the rail, which is the normal motion mode of the wheel, is simulated. This is done by applying 
the proper boundary conditions on the pilot node in the full model. For 3D elasto-plastic contact analysis, it is usually very time-consuming, even using the sub-modeling techniques. It is important to use the steady-state stress response within the mechanical components for the fatigue life prediction. We followed the method described in Liu et al. [25] to balance the computational effort and analysis accuracy for the current 3D finite element model. The stress responses after two cycles are assumed to be stabilized values and used for fatigue life prediction [26].

\section{The influence of rail chill on crack growth in a railway wheel due to braking loads}

Block braking of a wagon or a locomotive is performed by pressing the brake block(s) against the tread of the wheel, which also is in rolling contact with the rail. The phenomenon of heat loss from a hot wheel through the contact area into a cold rail is called 'rail chill'. [28].

A simplified elastic analysis of an idealized braked rail-car wheel subjected to periodic brakeshoe thermal shock, rail chill and realistic tractive rail contact stresses has been used to demonstrate the important thermal contributions to surface fatigue cracking using a critical plane fatigue initiation theory [29]. Some tests and experimental studies on the rail chill phenomenon have been reported in [30], [31]. Simple analytical procedures and semianalytical and numerical methods for calculating the wheel tread temperatures for both non-perfect thermal contact conditions and perfect thermal contact between wheel and rail are discussed in [32], [33], [34], [35]. [28].

An engineering tool, based on heat transfer principles, for estimating the temperature variation of the wheel rim was reported in [36] which also presented a method for calculating the rail chill effectiveness factor, i.e. the ratio of rail heat up and heat loss from wheel. In this work it was indicated that the rail chill effectiveness is fairly small for stop braking and rather large for drag braking. Twodimensional finite element models for the analysis of the temperature during railway tread braking (block(s) and wheel are coupled via a contact interface that controls the heat generation and also the heat partitioning between the block and the wheel through thermal contact resistances) have been provided and are presented in three parallel papers [37], [38], [39]. [28].

This tool can be used for calculating temperatures during a full train route, including gradient braking and stop braking with intermediate cooling periods. There are several ways to addresses the thermal behavior of the block-wheel-rail system and to determine the temperature fields in the wheels and in the brake blocks. One approach is to use a prescribed frictional heat (introduced) at the block-wheel interface. The focus of the [37] was on the development of a numerical model used for analyzing heat partitioning and temperatures in brake test rig experiments [38]. [28].

However, only wheel and block interaction was considered and the rail chill effect was ignored. This approach was further developed in [39] to simulate the thermal interaction of wheel, blocks, and rail during braking and after cool down. It was stated that calibrated models can be used for studying changes in wheel behaviors due to different block configurations and materials and that it can be used to study the difference in wheel behaviors between a brake test rig and operation in revenue traffic by accounting for the cooling influence at the wheel-rail contact. The influence of different wheel steel materials on the formation of the phase transformation zone of the wheel tread under high speed and heavy thermal load conditions is discussed in [40], [28].

During the braking process, the friction generated by the brake-shoe on the moving tread produces heating. The heat generation at the braking shoewheel interface and heat transfer to the rail is shown schematically in Fig. 11. [28].

A break cycle includes breaking to full stop. As the wheel rotates points on the wheel tread, experience both heating and cooling. The conditions at the two thermal contact interfaces which are associated with the wheel-rail and brake-wheel interfaces are very complex. [28].

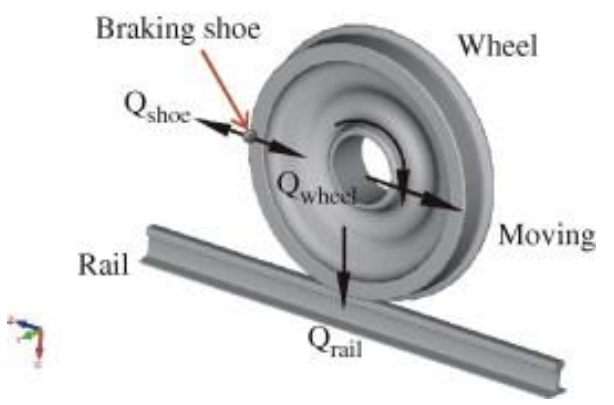

Fig. 11. Graphical representation of the rail chill effect [28]

Many factors, such as roughness of the surfaces, oxides, lubricant, organic material and sand, may cause a non-zero thermal contact (i.e. imperfect contact). In this analysis the interface thermal contact resistance has been ignored and the widely used assumption [41], [42], [43], [29], [37], [38], [39] of perfect thermal contact between the two surfaces has been adopted.[28].

\section{CONCLUDING REMARKS}

Ekberg and Kabo [1] present an overview of rolling contact fatigue phenomena occurring at wheels and rails and demonstrate some differences of RCF with classic fatigue analysis.

Hossein Tehrani and Saket [44] studied the fatigue crack initiation life of railroad wheels but 
effects of thermal and mechanical loads of braking were ignored and rolling of wheel was not modeled.

Haidari and Hosseini Tehrani [45] researched on the fatigue of railway wheels under combined thermal and mechanical loads but in their paper the crack was not modeled, and fracture life of wheel wasn't studied.

Some recent research on the braking thermal stresses and crack analysis and assumptions used are as follow:

Guagliano and Vergani [22], used a semianalytical approach for analysis of internal cracks in railway wheels.

Lansler and Kabo [46], proposed a 2D Finite Element model to get the face displacement of internal cracks in wheels.

Liu et al. [26] using the computational finite element method, calculated the history of stress intensity factor of the 3D rail- wheel contact stress.

Feng et al. [47] studied the growth behavior of subsurface cracks under different load paths and concluded that the models based on strain energy release rate cannot embrace this effect and a mixed mode crack growth model is necessary.

Yevtushenko and Kuciej [48] proposed an analytical solution for determination of temperature and thermal stresses in the pad-disc contact area and thermal cracks in this region.

Gallardo-Hernandez et al. [49] used the twin- disc test approach for studying abrasion and rolling contact fatigue of wheels and obtained temperature of each disc (which are corresponding to rail and wheel) by a thermo-camera.

Peng et al. [50] provided a prediction of the crack growth due to cyclic braking loads, mechanical loads, and residual stresses due to manufacturing process in the railway wheels. They used a 3D non-linear FE model to calculate thermal stress of the wheel; but in their work, blocks were not been modeled and average brake power was applied to the tread region of the wheel uniformly, therefore effects of local heating of wheel were not considered.

\section{ACKNOWLEDGEMENTS}

This paper presents a series of studies by reviewing the authors that focused their work on the wear of the wheels of railway vehicles in contact with the steering track (rail) to fatigue "Rolling contact fatigue" (RCF), for which I am grateful.

\section{REFERENCES}

[1] Ekberg A., Kabo E. (2005) Fatigue of railway wheels and rails under rolling contact and thermal loading - an overview, Wear, 258, pp. 1288-1300.

[2] Tyfour W.R., Beynon J.H., Kapoor A. (1996) Deterioration of rolling contact fatigue life of pearlitic rail steel due to dry-wet rolling-sliding line contact, Wear, 197 pp. 255-265.
[3] Ghonem H., Kalousek J. (1986) Surface crack initiation due to biaxial compression/shear loading, Proceedings of the Conference on Contact Mechanics and Wear of Rail/Wheel Systems II, University of Waterloo Press, Kingstone, RI, USA, pp. 339-360.

[4] Su X., Clayton P. (1997) Ratchetting strain experiments with a pearlitic steel under rolling/sliding contact, Wear, 205 pp. 137-143.

[5] Ringsberg J., (2000) Rolling contact fatigue of railway rails with emphasis on crack initiation, $\mathrm{PhD}$ Thesis, Department of Solid Mechanics, Chalmers University of Technology, Göteborg, Sweden.

[6] Kapoor A. (1994) A reevaluation of the life to rupture of ductile metals by cyclic plastic strain, Fatigue Fract Eng Mater Struct, 17 pp. 201-219.

[7] Ekberg A., Sotkovszki P. (2001) Anisotropy and fatigue of railway wheels, Int. J. Fatigue, 23 pp. $29-43$.

[8] Bower A.F. (1988) The influence of crack face friction and trapped fluid on surface initiated rolling contact fatigue cracks, ASME Journal of Tribology, 110, pp. 704-711.

[9] Ekberg A., Åkesson B., Kabo E., (2014) Wheel/ rail rolling contact fatigue - Probe, predict, prevent, Wear, 314, pp. 2-12.

[10] Deuce R., (2007) Wheel Tread Damage-An Elementary Guide, Bombardier Transportation GmbH, Netphen, Germany, Technical Report.

[11] Magel E., Kalousek J. (1996) Identifying and interpreting railway wheel defects, Proc. Intern. Heavy Haul Conference "Running heavy, running fast into the 21 st century”, Montreal, pp. 5.7-5.21.

[12] Gullers P., Dreik P., Nielsen J.C.O., Ekberg A., Andersson L. (2010) Track condition analyser: identification of rail rolling surface defects, likely to generate fatigue damage in wheels, using instrumented wheelset measurements, Proc. Inst. Mech. Eng. Part F: J. Rail Rapid Transit, pp. 1-13.

[13] Ekberg A., Marais J., (2000) Effects of imperfections on fatigue initiation in railway wheels, Proc. Inst. Mech. Eng. Part F: J. Rail Rapid Transit, 214(F1), pp. 45-54.

[14] Kabo E., Ekberg A. (2002) Fatigue initiation in railway wheels - a numerical study of the influence of defects, Wear, 253, pp. 26-34.

[15] Kabo E. (2002) Material defects in rolling contact fatigue-influence of overloads and defect clusters, Int. J. Fatigue, 24(8), pp. 887-894.

[16] Kabo E., Ekberg A. (2005) Material defects in rolling contact fatigue of railway wheels - the influence of defect size, Wear, 258(7-8), pp. 12881300 .

[17] Sandström J., de Maré J. (2011) Probability of subsurface fatigue initiation in rolling contact, Wear, 271, pp. 143-147.

[18] Ekberg A., Marais J. (2000) Effects of imperfections on fatigue initiation in railway wheels, Proc. Inst. Mech. Eng. Part F: J. Rail Rapid Transit, 214, pp. 45-54 
[19] Skyttebol A. (2004) Continuous welded railway rails: residual stress analyses, fatigue assessments and experiments, Ph.D. dissertation, Chalmers University of Technology.

[20] Nielsen J.C.O., Ekberg A., Lundén R. (2005) Influence of short-pitch wheel/rail corrugation on rolling contact fatigue of railway wheels, Proc. Inst. Mech. Eng. Part F: J. Rail Rapid Transit, 219(3), pp. 177-187.

[21] Ekberg A., Kabo E., Nielsen J.C., Lundén R. (2007) Subsurface initiated rolling contact fatigue of railway wheels as generated by rail corrugation, Int J Solids Struct, 44(24), pp. 7975-7987.

[22] Guagliano M., Vergani L. (2005) Experimental and numerical analysis of sub-surface cracks in railway wheels, Engineering Fracture Mechanics, 72, pp. 255-269.

[23] Timoshenko S.P., Goodier J.N. (1988) Theory of elasticity, McGraw-Hill International Editions, Singapore.

[24] Bryant M.D., Keer L.M. (1982) Rough contact between elastically and geometrically identical curved bodies, ASME J. Appl. Mech, 49, pp. 345-352.

[25] Liu Y., Stratman B., Mahadevan S. (2006) Fatigue crack initiation life prediction of railroad wheels, Int J Fatigue, 28(7), pp. 747-756.

[26] Liu Y., Liu L., Mahadevan S. (2007) Analysis of subsurface crack propagation under rolling contact loading in railroad wheels using FEM, Engineering Fracture Mechanics, 74(17) pp. 2659-2674

[27] *** AAR (Association of American Railroads). Manual of standards and recommended practices: section G. Wheels and axles, M-107/208, (1998).

[28] Peng D., Jones R., Constable T. (2013) An investigation of the influence of rail chill on crack growth in a railway wheel due to braking loads, Engineering Fracture Mechanics, 98, pp. 1-14.

[29] Moyar G.J., Stone D.H. (1991) An analysis of the thermal contributions to railway wheel shelling, Wear, 144(2), pp. 117-138.

[30] Stone D.H., Carpenter G.F. (1994) Wheel thermal damage limits, Proceedings of the 1994 ASME/IEEE Joint (in conjunction with area 1994 annual technical conference).

[31] Stone D.H., Moyar G.J. (1989) Wheel shelling and spalling - an interpretive review, Proc. ASME Winter Annual Meet.

[32] Moyar G.J., Carlson F.G. (1997), Simple method for estimating railcar wheel tread temperature rise during braking, Rail Transport, ASME, 13 pp. $65-74$

[33] Bejan A. (1989) Theory of rolling contact heat transfer, J Heat Transfer Trans ASME, 111(2) pp. 257-263.

[34] Moyar G.J., Carpenter G.F., Rajkumar B. R. (1986) Heat transfer experiments with braked railcar wheels, ASME paper 86-WA/RT-1.

[35] Ertz M., Knothe K. (2002) A comparison of analytical and numerical methods for the calculation of temperatures in wheel/rail contact, Wear, 253(34), p. $498-508$

[36] Crowe K.E., Raj P.K. (1998) Analyses of rail chill effect, DOT/FRA/ORD-97-07, U.S. Department of Transportation.

[37] Vernersson T. (2007) Temperatures at railway tread braking. Part 1: modelling, Proc I MECH E Part F. J Rail Rapid Transit, 221(2) pp. 167-182.

[38] Vernersson T. (2007) Temperatures at railway tread braking. Part 2: Calibration and numerical examples, Proc I MECH E Part F. J Rail Rapid Transit, 221(4), pp. 429-441.

[39] Vernersson T., (2007) Temperatures at railway tread braking. Part 3: wheel and block temperatures and the influence of rail chill, Proc Inst Mech Eng Part F: J Rail Rapid Transit, 221(4), pp. 443-454.

[40] Hang S.U., Tao P., Li L., Yang C.F., Cui Y.H., H. Z. (2008) Frictional heat-induced phase transformation on train wheel surface, J Iron Steel Res, 15(5), pp. 49-55.

[41] Lunden R., (1991) Contact region fatigue of railway wheels under combined mechanical rolling pressure and thermal brake loading, Wear, 144(1), pp. 57-70.

[42] Orringer O., Geay D.E. (1995) Thermal cracking in railroad vehicle wheels subjected to high performance stop braking, Theor Appl Fract Mech, 23, pp. 55-65.

[43] Donzella G., Scepi M., Trombini F., (1998), The effect of block braking on the residual stress state of a solid railway wheel, Proc Inst Mech Eng ProQuest Sci J, 212(2), pp. 145-158

[44] Tehrani H. P., Saket M. (2009) Fatigue crack initiation life prediction of railroad, Journal of Physics: Conference series, 181, pp. 53-63.

[45] Haidari, A., Tehrani H. P., (2014) Fatigue analysis of Railway wheels under combined thermal and mechanical loads, Journal of Thermal Stresses, 37, pp. 34-50.

[46] Lansler E., Kabo E. (2005) Subsurface crack face displacements in railway wheels, Wear, 258, pp. 1038-1047.

[47] Feng M., Ding F., Jiang Y. (2006) A study of loading path influence on fatigue crack growth under combined loading, International Journal of Fatigue, 28, pp.19-27.

[48] Yevtushenko A., Kuciej M. (2010) Temperature and thermal stresses in a pad/disc during braking, Applied Thermal Engineering, 30, pp. 354359.

[49] Gallardo-Hernandez E.A., Lewis R., DwyerJoyce R.S. (2006) Temperature in a twin-disc wheel/ rail contact simulation, Tribology International, 39, pp. 1653-1663.

[50] Peng D., Jones R., Constable T. (2013) An investigation of the influence of rail chill on crack growth in a railway wheel due to braking loads, Engineering Fracture Mechanics, 98, pp.1-14. 